\title{
Effect of frequency on pressure cost of ventilation and gas exchange in newborns receiving high-frequency oscillatory ventilation
}

\author{
Emanuela Zannin ${ }^{1}$, Raffaele L. Dellaca'1 , Giulia Dognini ${ }^{2}$, Lara Marconi ${ }^{1}$, Martina Perego ${ }^{1}$, Jane J. Pillow ${ }^{3}$, Paolo E. Tagliabue ${ }^{2}$ \\ and Maria Luisa Ventura ${ }^{2}$
}

BACKGROUND: We hypothesized that ventilating at the resonant frequency of the respiratory system optimizes gas exchange while limiting the mechanical stress to the lung in newborns receiving high-frequency oscillatory ventilation (HFOV). We characterized the frequency dependence of oscillatory mechanics, gas exchange, and pressure transmission during HFOV.

METHODS: We studied 13 newborn infants with a median (interquartile range) gestational age of $29.3(26.4-30.4)$ weeks and body weight of $1.00(0.84-1.43) \mathrm{kg}$. Different frequencies $(5,8,10,12$, and $15 \mathrm{~Hz})$ were tested, keeping carbon dioxide diffusion coefficient $\left(\mathrm{DCO}_{2}\right)$ constant. Oscillatory mechanics and transcutaneous blood gas were measured at each frequency. The attenuation of pressure swings $(\triangle P)$ from the airways opening to the distal end of the tracheal tube $(T T)$ and to the alveolar compartment was mathematically estimated.

RESULTS: Blood gases were unaffected by frequency. The mean (SD) resonant frequency was $16.6(3.5) \mathrm{Hz}$. Damping of $\Delta P$ increased with frequency and with lung compliance. $\Delta P$ at the distal end of the $\Pi$ was insensitive to frequency, whereas $\triangle P$ at the peripheral level decreased with frequency.

CONCLUSION: There is no optimal frequency for gas exchange when $\mathrm{DCO}_{2}$ is held constant. Greater attenuation of oscillatory pressure at higher frequencies offers more protection from barotrauma, especially in patients with poor compliance.

$T^{1}$ he mechanisms governing gas flow, gas exchange, and pressure transmission during high-frequency oscillatory ventilation (HFOV) are fundamentally different than those at physiological breathing rates: these HFOV-specific mechanisms are strongly dependent on the mechanical characteristics of the respiratory system and on the oscillatory frequency (1).

To date, the selection of frequency is rather arbitrary in clinical practice. The rationale behind frequency selection should be to achieve adequate alveolar ventilation at minimal pressure cost to both proximal and distal lung compartments (1). Venegas et al. (2) divided this problem into two simpler problems: the pressure cost of flow and the flow cost of ventilation. The pressure cost of flow is determined by the mechanical properties of the respiratory system and specifically by respiratory system impedance $\left(Z_{\mathrm{rs}}\right)$. $Z_{\mathrm{rs}}$ is frequency-dependent and its magnitude is minimized at the resonance frequency $\left(f_{0}\right)$. The flow cost of ventilation increases with increasing frequency, and the rate of increase is much higher for frequencies above $5 \mathrm{~Hz}$. According to the model calculations of Venegas et al. (2), the frequency that allows adequate gas transport at the minimal pressure cost is around $f_{0}$. The pressure cost of ventilation to the distal compartment also depends on pressure swings' transmission, which also depends on frequency and lung mechanics. Studies on excised animal lungs showed that alveolar pressure swings may exceed pressure swings at the airways opening for frequencies close to $f_{0}$ (refs 3-5). However, unlike the dog's lung, the infant's respiratory system is very likely an overdamped system and pressure swings can be expected to be attenuated at the peripheral level, with the damping depending on frequency and lung mechanics. Several studies carried out on theoretical $(6,7)$, in vitro (8), and animal models $(7,9)$ showed that the transmission of pressure amplitude to both the tracheal $(6,7,9)$ and the alveolar compartments $(7,8)$ is strongly determined by lung compliance, with low values of compliance being associated with higher pressure transmission. However, these results have never been confirmed in newborn infants.

We hypothesized that the optimal oscillatory frequency depends on lung mechanics and specifically that $f_{0}$ would optimize gas exchange while minimizing the mechanical stress to the lung. It has been recently shown that changes in oscillatory lung mechanics can be assessed during HFOV without suspending or modifying ventilation (8). Specifically, respiratory system impedance $\left(Z_{\mathrm{rs}}\right)$ can be evaluated from the mechanical response of the respiratory system to the oscillatory waveform delivered by the ventilator. $Z_{\mathrm{rs}}$ is

\footnotetext{
${ }^{1}$ Dipartimento di Elettronica, Informazione e Bioingegneria, Politecnico di, Milano University, Milan, Italy; ${ }^{2}$ Obstetric and Pediatric Department, Neonatal Intensive Care Unit, Fondazione MBBM-ASST, Monza, Italy; ${ }^{3}$ Centre for Neonatal Research and Education, School of Anatomy, Physiology and Human Biology, University of Western Australia, Perth, WA, Australia. Correspondence: Emanuela Zannin (emanuela.zannin@polimi.it) 


\section{Frequency selection in newborns on HFOV Articles}

commonly expressed in terms of resistance $\left(R_{\mathrm{rs}}\right)$ and reactance $\left(X_{\mathrm{rs}}\right)$, the latter representing the elastic and inertive properties of the system. The frequency at which inertial and elastic properties cancel and $X_{\mathrm{rs}}$ is zero is $f_{0}$.

The aim of the present study was to characterize the relationship between frequency and gas exchange, oscillatory mechanics, and pressure transmission in newborns receiving $\mathrm{HFOV}$ at constant $\mathrm{DCO}_{2}$.

\section{METHODS}

Measurements were performed in the neonatal intensive care unit of Fondazione MBBM-ASST-Monza, Italy. The study was approved by the local ethical committee, and informed parental consent was obtained before the studies.

\section{Study Population}

Infants receiving HFOV were eligible if they had no pneumothorax or pneumomediastinum, congenital heart diseases, or other malformations relevant to lung function.

\section{Experimental Protocol}

Infants were placed in supine position and connected to a HighFrequency Oscillatory Ventilator (Sensormedics 3100A, CareFusion, San Diego, CA).

The mean airway pressure was optimized for each patient before baseline observations using an open lung approach (10). The $\mathrm{DCO}_{2}$ $\left(\mathrm{DCO}_{2}=f \cdot V_{\mathrm{T}}^{2}\right.$, where $f$ is the oscillatory frequency and $V_{\mathrm{T}}$ is the tidal volume) was adjusted to maintain $\mathrm{tcPCO}_{2}$ between 40 and $60 \mathrm{~mm} \mathrm{Hg}$.

For each study participant, oscillatory frequency was changed between $5,8,10,12$, and $15 \mathrm{~Hz}$ in a random sequence. At each frequency, tidal volume was adjusted to keep $\mathrm{DCO}_{2}$ constant by modifying the oscillatory pressure amplitude.

$I: E$ was set to $1: 1$, as the mean peripheral airway pressure changes when frequency is changed with an I:E different than 1:1 (11).

$Z_{\mathrm{rs}}$ and transcutaneous blood gases were measured for each frequency, after a 10 -min stabilization period.

\section{Measurements and Monitoring}

Pressure $\left(P_{\mathrm{ao}}\right)$ and flow $\left(V_{\mathrm{ao}}^{\prime}\right)$ were measured at the airway opening (Florian, Acutronic Medical Systems, Hirzel, Switzerland). The signals were sampled at $240 \mathrm{~Hz}$ (OEP System, BTS, Milano, Italy) and stored on a desktop computer. The frequency response of the measuring system was characterized on a bench model of preterm lung. Subsequent measurements were compensated for the frequency response of the system. $Z_{\text {rs }}$ was measured by the forced oscillation technique without suspending ventilation, by analyzing the mechanical response of the respiratory system to the oscillatory pressure delivered by the ventilator (12).

Transcutaneous partial pressure of oxygen $\left(\mathrm{tc} P \mathrm{O}_{2}\right)$ and carbon dioxide $\left(\mathrm{tc} P \mathrm{CO}_{2}\right)$ was measured (Radiometer, Copenaghen, Denmark). Peripheral oxygen saturation and heart rate were monitored continuously (DataScope, Mahwah, NJ).

\section{Data Analysis}

$Z_{\mathrm{rs}}$ was estimated from $P_{\mathrm{ao}}$ and $V_{\mathrm{ao}}^{\prime}$ using the cross-spectrum method (13). $Z_{\mathrm{rs}}$ values with coherence lower than 0.97 were discarded. The magnitude of $Z_{\mathrm{rs}}\left(\left|Z_{\mathrm{rs}}\right|\right)$ represents the pressure cost to deliver a unit of flow. $Z_{\mathrm{rs}}$ was also expressed as resistance $\left(R_{\mathrm{rs}}\right)$ and reactance $\left(X_{\mathrm{rs}}\right)$. The contribution of the tracheal tube (TT) to total $Z_{\mathrm{rs}}$ was estimated as described in the Supplementary Digital Appendix online and subtracted.

Impedance data were fitted to a mathematical model composed of a flow-dependent resistance connected in series with a series combination of resistance, inertance $(I)$, and compliance $(C)$. Model parameters were used to estimate $f_{0}\left(1 /\left[2 \pi(I C)^{1 / 2}\right]\right.$ (ref. 14)) and the pressure swings' attenuation from the airways opening to the distal end of the TT and to the alveolar compartment.

\section{Statistical Analysis}

Some infants were measured at different stages of lung disease, and each measure was considered as an independent case. Significance of differences in gas exchange between frequencies was tested by oneway ANOVA for repeated measures. Spearman correlation was used to evaluate the correlation between lung mechanics parameters and the damping of pressure swings.

\section{RESULTS}

In total, 13 newborn infants (seven males and six females) with a median (interquartile range) gestational age of 29.3 (26.4-30.4) weeks were studied. The median (interquartile range) postnatal age was $2.5(1.0-6.0)$ days, and the weight at the time of the study was $1.00(0.84-1.43) \mathrm{kg}$. There was no correlation between target $\mathrm{DCO}_{2} / \mathrm{wt}^{2}$ and basal $\mathrm{tc} P \mathrm{PO}_{2}$ $\left(R^{2}=0.01, P>0.05\right)$. The characteristics of each patient, the oscillatory settings, and blood gases at baseline are reported in Supplementary Table S1.

Figure 1 shows the relationship between ventilation frequency and gas exchange. Both oxygenation $\left(\mathrm{tc} P \mathrm{O}_{2} / \mathrm{FiO}_{2}\right)$ and $\mathrm{tc} P \mathrm{CO}_{2}$ were not significantly affected by frequency.

Figure 2 shows the relationship between frequency and $\left|Z_{\mathrm{rs}}\right|$ (Figure 2a), $R_{\mathrm{rs}}$ (Figure 2b), and $X_{\mathrm{rs}}$ (Figure 2c). Total $\left|Z_{\mathrm{rs}}\right|$ presented a minimum at $8 \mathrm{~Hz}$, whereas $\left|Z_{\mathrm{rs}}\right|$ corrected from the contribution of the TT presented a broad plateau from 8 to $15 \mathrm{~Hz}$. Total $R_{\mathrm{rs}}$ slightly increased with frequency, whereas $R_{\mathrm{rs}}$ corrected for the contribution of the TT was independent from frequency, suggesting that the frequency dependence of total $R_{\mathrm{rs}}$ was mainly because of the TT. Total $X_{\mathrm{rs}}$ increased with frequency and crossed the $x$ axis at $f_{0}$. After subtracting

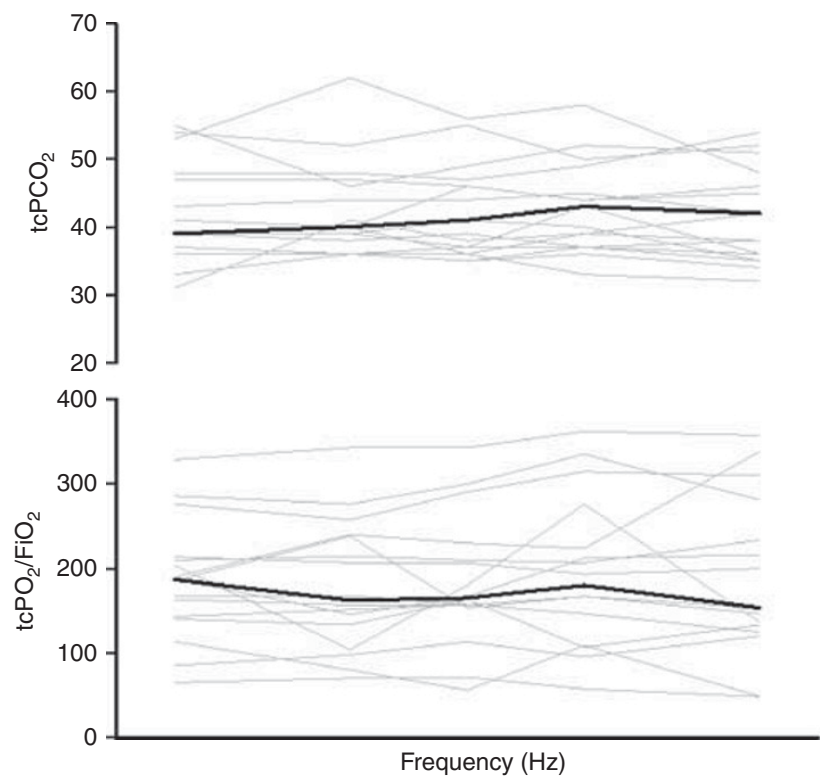

Figure 1. Transcutaneous $t c \mathrm{PO}_{2} / \mathrm{FiO}_{2}$ (bottom) and tcPCO (top). Gray lines represent individual infants; bold black lines represent the median values. 

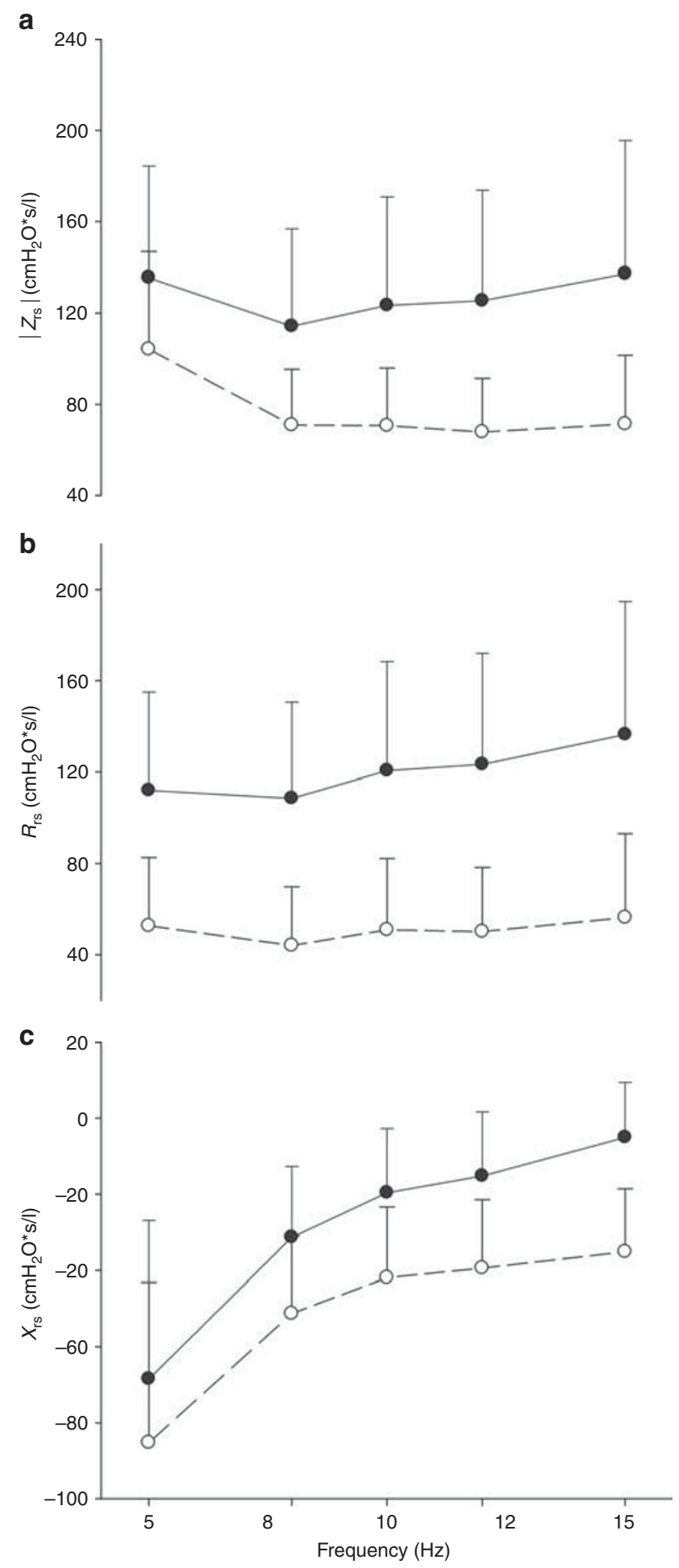

Figure 2. Relationship between frequency and respiratory system impedance expressed as magnitude $\left(\left|Z_{\mathrm{rs}}\right|, \mathbf{a}\right)$, resistance $\left(R_{\mathrm{rs}}, \mathbf{b}\right)$, and reactance $\left(X_{\mathrm{rs},}, \mathbf{c}\right)$. Closed symbols, solid lines refer to the total respiratory system including the $\Pi$. Open symbols, dashed lines refer to the respiratory system below the $\Pi$. Data are expressed as mean and SD. TT, tracheal tube.

the contribution of the TT, $X_{\text {rs }}$ remained negative, suggesting that the mechanical behavior of the respiratory system below the TT was mainly elastic.
Table 1. Mechanical characteristics of the patients' respiratory system

\begin{tabular}{|c|c|c|c|c|c|}
\hline Patient & $\begin{array}{c}\text { Mean } R_{\pi} \\
\left(\mathrm{cmH}_{2} \mathrm{O} \cdot \mathrm{s} / \mathrm{l}\right)\end{array}$ & $I\left(\mathrm{cmH}_{2} \mathrm{O} \cdot \mathrm{s}^{2} / \mathrm{l}\right)$ & $\begin{array}{c}R_{\text {Irs }} \\
\left(\mathrm{cmH}_{2} \mathrm{O} \cdot \mathrm{s} / \mathrm{l}\right)\end{array}$ & $\begin{array}{c}\mathrm{C}(\mathrm{ml} / \\
\left.\mathrm{cmH}_{2} \mathrm{O}\right)\end{array}$ & $f_{0}(\mathrm{~Hz})$ \\
\hline 1 & 93.5 & 0.21 & 0.0 & 0.19 & 25.53 \\
\hline $1 \mathrm{Bis}$ & 95.0 & 0.10 & 19.5 & 0.97 & 16.18 \\
\hline 2 & 83.0 & 0.15 & 67.3 & 0.46 & 19.43 \\
\hline 2 Bis & 22.7 & 0.13 & 62.9 & 0.73 & 16.27 \\
\hline 3 & 68.0 & 0.16 & 48.2 & 0.43 & 19.17 \\
\hline 4 & 127.9 & 0.25 & 115.0 & 0.26 & 19.95 \\
\hline 5 & 60.5 & 0.50 & 48.7 & 0.30 & 13.00 \\
\hline 6 & 27.6 & 0.10 & 31.9 & 1.46 & 13.16 \\
\hline 7 & 21.3 & 0.28 & 82.7 & 0.42 & 14.73 \\
\hline 8 & 154.8 & 0.12 & 54.3 & 1.05 & 14.17 \\
\hline 9 & 49.9 & 0.38 & 88.6 & 0.43 & 12.41 \\
\hline 9 Bis & 63.4 & 0.18 & 52.5 & 0.49 & 16.80 \\
\hline 10 & 33.9 & 0.28 & 66.9 & 0.28 & 18.02 \\
\hline 11 & 33.6 & 0.10 & 44.1 & 0.66 & 19.59 \\
\hline 12 & 69.5 & 0.24 & 40.8 & 0.53 & 14.06 \\
\hline 13 & 79.8 & 0.20 & 14.5 & 0.74 & 13.19 \\
\hline Mean & 69.4 & 0.21 & 50.7 & 0.59 & 16.60 \\
\hline SD & 36.5 & 0.11 & 28.9 & 0.34 & 3.53 \\
\hline
\end{tabular}

Bis, second measurement; $C$, compliance; $f_{0}$, resonant frequency; $I$, inertance; $R_{\text {Irs, }}$ resistance of lower respiratory system; $R_{\pi}$, resistance of the tracheal tube.

Table 2. Pressure amplitudes as a function of frequency and tidal volumes

\begin{tabular}{|c|c|c|c|c|}
\hline$f(\mathrm{~Hz})$ & $\Delta P_{\text {ao }}\left(\mathrm{cmH}_{2} \mathrm{O}\right)$ & $\Delta P_{\mathrm{tr}}\left(\mathrm{cmH}_{2} \mathrm{O}\right)$ & $\Delta P_{\text {alv }}\left(\mathrm{cmH}_{2} \mathrm{O}\right)$ & $V_{\mathrm{T}}(\mathrm{ml} / \mathrm{kg})$ \\
\hline 5 & $23.37 \pm 7.87$ & $16.40 \pm 8.18$ & $12.80 \pm 8.31$ & $3.03 \pm 0.99$ \\
\hline 8 & $25.24 \pm 7.33$ & $15.06 \pm 6.89$ & $9.51 \pm 6.45$ & $2.49 \pm 0.75$ \\
\hline 10 & $29.72 \pm 7.95$ & $16.18 \pm 6.70$ & $8.79 \pm 5.21$ & $2.26 \pm 0.72$ \\
\hline 12 & $32.56 \pm 8.89$ & $16.65 \pm 7.34$ & $7.93 \pm 4.79$ & $2.00 \pm 0.62$ \\
\hline 15 & $40.07 \pm 9.11$ & $18.60 \pm 7.71$ & $7.44 \pm 4.33$ & $1.80 \pm 0.55$ \\
\hline
\end{tabular}

Table 1 reports the mechanical characteristics of the individual patients. On average, the resistance of the TT $\left(R_{\mathrm{TT}}\right.$, mean across all frequencies) was $69 \pm 36 \mathrm{cmH}_{2} \mathrm{O} \cdot \mathrm{s} / \mathrm{l}$, the resistance of the lower respiratory system $\left(R_{\mathrm{lrs}}\right)$ was $48 \pm 28 \mathrm{cmH}_{2} \mathrm{O} \cdot \mathrm{s} / \mathrm{l}$, compliance $(C)$ was $0.6 \pm 0.3 \mathrm{ml} / \mathrm{cmH}_{2} \mathrm{O}$, inertia $(I)$ was $0.2 \pm 0.2 \mathrm{cmH}_{2} \mathrm{O} \cdot \mathrm{s}^{2} / \mathrm{l}$, and $f_{0}$ was $16.6 \pm 3.5 \mathrm{~Hz}$ in agreement with previous reports (14-16).

Table 2 reports, for each oscillatory frequency, the amplitude of pressure swings measured at the airways opening $\left(\Delta P_{\mathrm{ao}}\right)$, the estimates of pressure swings at the distal end of the TT $\left(\Delta P_{\mathrm{tr}}\right)$, and in the alveolar compartment $\left(\Delta P_{\text {alv }}\right)$, and the measured $V_{\mathrm{T}}$. To maintain $\mathrm{DCO}_{2}$ constant, $V_{\mathrm{T}}$ was reduced with frequency, from $3.0 \pm 1.0 \mathrm{ml} / \mathrm{kg}$ at $5 \mathrm{~Hz}$ to $1.8 \pm 0.6 \mathrm{ml} / \mathrm{kg}$ at $15 \mathrm{~Hz}$, and $\Delta P_{\text {ao }}$ was increased, passing from $24 \pm 8 \mathrm{cmH}_{2} \mathrm{O}$ at $5 \mathrm{~Hz}$ to $40 \pm 9 \mathrm{cmH}_{2} \mathrm{O}$ at $15 \mathrm{~Hz} . \Delta P_{\text {ao }}$ 
was strongly damped down the proximal airways and the fraction of $\Delta P_{\mathrm{ao}}$ transmitted to the distal compartments of the lung decreased with frequency. As a result, $\Delta P_{\operatorname{tr}}$ was almost independent from frequency (ranging from $15 \pm 7 \mathrm{cmH}_{2} \mathrm{O}$ at $8 \mathrm{~Hz}$ to $19 \pm 8 \mathrm{cmH}_{2} \mathrm{O}$ at $15 \mathrm{~Hz}$ ), whereas $\Delta P_{\text {alv }}$ decreased from $13 \pm 8 \mathrm{cmH}_{2} \mathrm{O}$ at $5 \mathrm{~Hz}$ to $8 \pm 4 \mathrm{cmH}_{2} \mathrm{O}$ at $15 \mathrm{~Hz}$.

Mathematical simulations confirmed that when frequency is changed while targeting a constant $\mathrm{DCO}_{2}$ value, the pressure cost of ventilation has the following effects: (i) increases with frequency at the airway opening; (ii) is independent of frequency at the distal end of the TT; and (iii) decreases with frequency in the alveolar compartment (Supplementary Digital Appendix).

The fraction of $\Delta P_{\text {ao }}$ transmitted to the distal end of the TT $\left(\Delta P_{\mathrm{tr}} / \Delta P_{\mathrm{ao}}\right)$ correlated significantly with both $R_{\mathrm{TT}}$ and $C$. The correlation with $C$ was stronger at low frequencies, whereas the correlation with $R_{\mathrm{TT}}$ was stronger at high frequencies. The fraction of $\Delta P_{\text {ao }}$ transmitted to the alveolar compartment $\left(\Delta P_{\text {alv }} / \Delta P_{\text {ao }}\right)$ was mainly determined by $C$ (Table 3 ). Peripheral resistance and inertia presented weaker correlation with pressure swings' attenuation.

\section{DISCUSSION}

We characterized the relationship between gas exchange, oscillatory mechanics, and pressure transmission in newborn infants receiving HFOV across a range of frequencies at constant $\mathrm{DCO}_{2}$. Oscillatory mechanics were assessed without suspending ventilation or modifying the mean airway pressure.

Our main findings are as follows: (i) provided that $\mathrm{DCO}_{2}$ is kept constant, there is no optimal frequency in terms of gas exchange, (ii) the pressure oscillations are strongly damped as they travel along the endotracheal tube and airways, and (iii) the damping of the pressure oscillations increases with frequency and is stronger in patients with higher compliance.

Table 3. $P$ values and correlation coefficients $(R)$ between $\Delta P_{\mathrm{tr}} / \Delta P_{\mathrm{ao}}$ and $\Delta P_{\text {alv }} / \Delta P_{\text {ao }}$ and the mechanical characteristics of the respiratory system

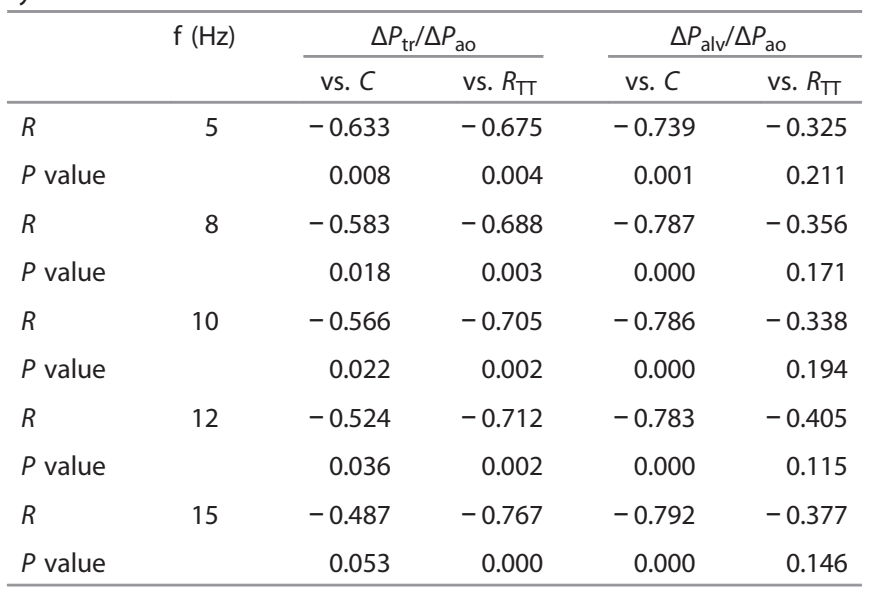

$C$, compliance; $\Delta P_{\text {alv, }}$ pressure amplitude in the alveolar compartment; $\Delta P_{\text {ao, }}$ pressure amplitude at the airways opening; $\Delta P_{\mathrm{tr}}$, pressure amplitude at the distal end of the tracheal tube; $R_{T}$, resistance of thetracheal tube.

\section{Relationship between Oscillatory Frequency and Gas Exchange} We hypothesized that $f_{0}$ would optimize gas exchange. On the contrary, we found that in our population of infants receiving $\mathrm{HFOV}$, frequency does not significantly affect gas exchange if $\mathrm{DCO}_{2}$ is maintained constant.

This result is in agreement with previous studies carried out using theoretical models (17), healthy animals, and humans (18-20), but it has never been confirmed in preterm babies. The studies referenced above showed that the efficacy of ventilation is proportional to $V_{\mathrm{T}}{ }^{a} f^{b}$ and that $a$ and $b$ approximate 2 and 1, respectively. However, it is important to recall that these constants may be influenced by several factors, such as the shape and complexity of the oscillatory pressure waveform. Our study was carried out using Sensormedics $3100 \mathrm{~A}$, which delivers square pressure waveforms, and we used an I:E ratio of 1:1; therefore, caution must be used to extend our results to different oscillators and settings. Moreover, we cannot exclude that the relationship between frequency and gas exchange might be different in different pathologies.

Even though we cannot draw any conclusion on how to select the target $\mathrm{DCO}_{2}$, it is interesting to notice that in our patients there was no correlation between $\mathrm{DCO}_{2}$ and $\mathrm{tc} P \mathrm{CO}_{2}$. This is in contrast with what Boynton et al. have observed in healthy rabbits (21) and may be related to the heterogeneity of our population in terms of pulmonary disease.

Moreover, the finding that frequency by itself does not influence gas exchange when a given $\mathrm{DCO}_{2}$ is targeted is of high clinical interest: (i) it supports the use of volume guarantee during HFOV; and (ii) it suggests that high frequencies offer the advantage of providing adequate ventilation with lower tidal volumes (22) and lower pressure swings at the peripheral level.

\section{Relationship between Oscillatory Frequency and Lung Mechanics}

Neonatologists use HFOV to reduce the risk of volutrauma and barotrauma. The rationale for frequency selection during HFOV is to minimize the pressure swings to both proximal and distal lung compartments while providing adequate ventilation to the patient. We aimed to understand how frequency selection influences pressure cost of ventilation in infants across a range of lung compliances. Ventilating infants at the resonance frequency of their respiratory system optimizes the efficiency of ventilation (16). However, when $\mathrm{DCO}_{2}$ is kept constant and flow is changed accordingly, the resonance frequency is not associated with the minimal pressure cost of ventilation.

The amplitude of pressure oscillations at the airways opening is the only oscillatory pressure amplitude that is visible to the clinician and mistakenly used to justify changes in frequency. However, the principal site for barotrauma in the noncompliant surfactant-deficient and structurally immature lung is the zone of interface between the relatively compliant airways and the poorly compliant lung parenchyma: indeed the junction of the terminal bronchioles with the 


\section{Articles | Zannin et al.}

acinar zone is key to the development of pulmonary interstitial emphysema $(23,24)$. As pressure swings in distal compartments are more relevant to barotrauma than pressure swings at the inlet of the TT, we used a mathematical model to estimate the pressure swings at the distal end of the TT and in the peripheral compartment. The pressure oscillations were strongly damped as they passed the TT, particularly at high frequency. As a result, frequency selection had minimal effect on the absolute pressure cost of ventilation at the tracheal level. Pressure swings were further damped at the alveolar level and decreased with increasing frequency. Consequently, the lowest pressure cost of ventilation for the lung parenchyma was evident at the highest frequency: completely the opposite scenario to pressure swings at the airway opening, which increased with increasing frequency. This contradiction is important clinically as the clinician only sees the pressure swings displayed by the ventilator, measured from the airway opening. Our findings underline the importance of understanding the implications of frequency selection for barotrauma and the inappropriate use of airway opening pressure swings by many clinicians as a justification for frequency selection.

Theoretical and animal $(4,5,7)$ studies show marked reduction in pressure transmission to the distal end of the TT with increasing compliance during alveolar recruitment. Our results confirm that compliance is a critical determinant of the oscillatory pressure transmitted to the airways and to the distal lung, but they also show that as frequency is increased the resistance of the TT becomes progressively more important in determining the fraction of oscillatory pressure that is transmitted to the trachea. The importance of $R_{\mathrm{TT}}$ in determining pressure transmission was previously reported by Pillow et al. (7). Using a computer model oscillated at $15 \mathrm{~Hz}$, the authors showed that the magnitude of $R_{\mathrm{TT}}$ and lung compliance are the principal determinants of the pressure transmission to the alveolar compartment and to the distal end of the TT. In our study, $R_{\mathrm{TT}}$ correlated strongly with the pressure transmission to the distal end of the TT but not as much with the pressure transmission to the alveolar compartment. In the simulations carried out by Pillow et al., peripheral resistance and its balance with compliance also had a significant role in determining the fraction of $\Delta P_{\text {ao }}$ transmitted to the tracheal compartment (7). On the contrary, we did not find a significant correlation between peripheral resistance and the transmission of pressure from the airways opening to either the tracheal or the alveolar compartments. The reason that we found a weaker correlation between pressure transmission and peripheral resistance might be that, although Pillow et al. maintained $\Delta P_{\mathrm{ao}}$ and frequency constant (7), we modified the frequency while $\mathrm{DCO}_{2}$ was maintained constant (therefore, $P_{\mathrm{ao}}$ and $V_{\text {ao }}^{\prime}$ changed accordingly).

Our results suggest that frequency selection does not influence the efficacy of $\mathrm{HFOV}$, provided that $\mathrm{DCO}_{2}$ is maintained constant.
On the contrary, the selection of frequency must be guided by the mechanical characteristics of the patient as they strongly influence the pressure cost of ventilation and the pressure transmission to the distal compartments. In particular, much of the pressure applied at the opening of airways is transmitted to the distant lung in infants with low compliance, especially at low frequencies. High frequency should be preferred when using HFOV in infants with low compliance because the high frequency facilitates pressure damping while still achieving the same ventilation obtained at lower tidal volumes. Pressure oscillations are markedly attenuated across a wider range of frequencies in patients with highly compliant lungs and therefore selecting high frequencies is not as important as in patients with low lung compliance. In contrast, the use of high frequency in patients ventilated with very small TTs (narrow diameter, high TT resistance) may be associated with a very high pressure cost of ventilation at the airway opening, but most of this cost is spent to move the flow through the TT and pressure swings are strongly damped at the level of the trachea.

Even though we did not measure any clinical outcome related to the mechanical stress applied to the lung, and therefore our conclusion is only speculative, our results suggest that higher frequencies offer more barotrauma protection.

\section{Limitations of the Study}

To estimate pressure swings at the carina and at the alveolar level, we used a mathematical model. However, the estimates must be taken with caution as they are based on a singlecompartment model of the respiratory system that assumes a homogeneous distribution of the mechanical characteristics of the lung. This is not an accurate representation of the true situation in the diseased lungs, which is often characterized by patchy areas of consolidation, atelectasis, and hyperinflation, leading to regional heterogeneities in the distribution of the amplitude of pressure oscillations, with regions having shorter time constants receiving higher pressure swings (7).

\section{CONCLUSION}

In our population of infants receiving HFOV, using frequencies up to $15 \mathrm{~Hz}$ keeping $\mathrm{DCO}_{2}$ constant did not affect gas exchange. Frequency should be selected based on the mechanical characteristics of the patient with a view to minimizing the pressure cost of ventilation for the lung parenchyma. High frequencies should be preferred, particularly in infants with low compliance, as they facilitate pressure damping.

\section{SUPPLEMENTARY MATERIAL}

Supplementary material is linked to the online version of the paper at http://www.nature.com/pr

Disclosure: The authors declare no conflict of interest.

\section{REFERENCES}

1. Pillow JJ. High-frequency oscillatory ventilation: mechanisms of gas exchange and lung mechanics. Crit Care Med 2005;33:S135-41. 


\section{Frequency selection in newborns on HFOV Articles}

2. Venegas JG, Fredberg JJ. Understanding the pressure cost of ventilation: why does high-frequency ventilation work? Crit Care Med 1994;22:S49-57.

3. Allen JL, Frantz ID, Fredberg JJ. Regional alveolar pressure during periodic flow: dual manifestations of gas inertia. J Clin Invest 1985;76:620-9.

4. Alleyne CM, Frantz ID, Fredberg JJ. Preferential axial flow during highfrequency oscillations: effects of gas density. J Appl Physiol 1989;66:542-7.

5. Fredberg JJ, Keefe DH, Glass GM, Castile RG, Frantz ID. Alveolar pressure nonhomogeneity during small-amplitude high-frequency oscillation. J Appl Physiol 1984;57:788-800.

6. Van Genderingen HR, Versprille A, Leenhoven T, Markhorst DG, Van Vught AJ, Heethaar RM. Reduction of oscillatory pressure along the endotracheal tube is indicative for maximal respiratory compliance during high-frequency oscillatory ventilation: a mathematical model study. Pediatr Pulmonol 2001;31:458-63.

7. Pillow JJ, Sly PD, Hantos Z, Bates JHT. Dependence of intrapulmonary pressure amplitudes on respiratory mechanics during high-frequency oscillatory ventilation in preterm lambs. Pediatr Res 2002;52:538-44.

8. Pillow JJ, Wilkinson MH, Neil HL, Ramsden CA. In vitro performance characteristics of high-frequency oscillatory ventilators. Am J Respir Crit Care Med 2001;164:1019-24.

9. Van Genderingen HR, Van Vught AJ, Duval ELIM, Markhorst DG, Jansen JRC. Attenuation of pressure swings along the endotracheal tube is indicative of optimal distending pressure during high-frequency oscillatory ventilation in a model of acute lung injury. Pediatr Pulmonol 2002;33:429-36.

10. De Jaegere A, van Veenendaal MB, Michiels A, van Kaam AH. Lung recruitment using oxygenation during open lung high-frequency ventilation in preterm infants. Am J Respir Crit Care Med 2006;174:639-45.

11. Pillow JJ, Neil H, Wilkinson MH, Ramsden CA. Effect of I/E ratio on mean alveolar pressure during high-frequency oscillatory ventilation. J Appl Physiol 1999;87:407-14.

12. Dellacà RL, Zannin E, Ventura ML, et al. Assessment of dynamic mechanical properties of the respiratory system during high-frequency oscillatory ventilation*. Crit Care Med 2013;41:2502-11.
13. Michaelson ED, Grassman ED, Peters WR. Pulmonary mechanics by spectral analysis of forced random noise. J Clin Invest 1975;56: 1210-30.

14. Dorkin HL, Stark AR, Werthammer JW, et al. Respiratory system impedance from 4 to $40 \mathrm{~Hz}$ in paralyzed intubated infants with respiratory disease. J Clin Invest 1983;72:903-10.

15. Lee S, Milner AD. Resonance frequency in respiratory distress syndrome. Arch Dis Child Fetal Neonatal Ed 2000;83:F203-6.

16. Lee S, Alexander J, Blowes R, Ingram D, Milner AD. Determination of resonance frequency of the respiratory system in respiratory distress syndrome. Arch Dis Child Fetal Neonatal Ed 1999;80: F198-202.

17. Fredberg JJ. Augmented diffusion in the airways can support pulmonary gas exchange. J Appl Physiol 1980;49:232-8.

18. Rossing TH, Slutsky AS, Lehr JL, Drinker PA, Kamm R, Drazen JM. Tidal volume and frequency dependence of carbon dioxide elimination by high-frequency ventilation. N Engl J Med 1981;305:1375-9.

19. Slutsky AS. Gas mixing by cardiogenic oscillations: a theoretical quantitative analysis. J Appl Physiol 1981;51:1287-93.

20. Jaeger MJ, Kurzweg UH, Banner MJ. Transport of gases in high-frequency ventilation. Crit Care Med 1984;12:708-10.

21. Boynton BR, Hammond MD, Fredberg JJ, Buckley BG, Villanueva D, Frantz ID. Gas exchange in healthy rabbits during high-frequency oscillatory ventilation. J Appl Physiol 1989;66:1343-51.

22. González-Pacheco N, Sánchez-Luna M, Ramos-Navarro C, NavarroPatiño N, de la Blanca AR-S. Using very high frequencies with very low lung volumes during high-frequency oscillatory ventilation to protect the immature lung. A pilot study. J Perinatol 2016;36:306-10.

23. Sakai T, Aiba S, Takahashi R, Yoshioka T, Iinuma K. Pulmonary interstitial emphysema during piston-type high-frequency oscillatory ventilation. Tohoku J Exp Med 1996;180:327-5.

24. Nucci G, Suki B, Lutchen K. Modeling airflow-related shear stress during heterogeneous constriction and mechanical ventilation. J Appl Physiol 2003;95:348-56. 